\title{
Programa de emergencia ambulatorio para el cuidado de niños severamente desnutridos
}

Outpatient care for severely malnourished children in emergency relief programmes: a retrospective cohort study . Collins $S$ and Sadler K. The Lancet 2002: 360: 1824-30.

\begin{abstract}
Objetivo
Evaluar la efectividad de un programa de alimentación ambulatorio para el tratamiento de la desnutrición severa, en niños de 6 a120 meses de edad, implementado desde septiembre del 2000 a enero de 2001.
\end{abstract}

\section{Diseño}

Estudio retrospectivo de cohortes.

Lugar

Centros de atención ambulatoria, en Etiopía.

\section{Participantes}

Se evaluaron los registros clínicos de 170 niños con edades entre 6 a 120 meses, que habían tenido marasmo, kwashiorkor ó kwashiorkor-marasmo. Las variables evaluadas fueron mortalidad, no adherencia al programa, alta del programa, índice de aumento de peso y tiempo de permanencia en el programa.

\section{Resultados Principales}

La edad media de los participantes era 36 meses (IC 95\% 24-48). Del total de participantes, 106 niños tenían marasmo, 14 kwashiorkor-marasmo y 50 kwashiorkor. $144(85 \%)$ de los pacientes se recuperaron, siete $(4 \%)$ murieron, $11(6 \%)$ fueron derivados y ocho $(5 \%)$ no adhirieron al programa (ver tabla 1). El tiempo medio para el alta fue 42 días (IC 95\% 28-56), para la muerte 14 días (IC 95\% 7-26) y, para la no adherencia 14 días (7-28). En general la tasa media de ganancia de peso fue $316 \mathrm{~g} / \mathrm{día}$ (186-560). En los pacientes con marasmo la ganancia media de peso fue $480 \mathrm{~g} /$ día (295-807), en los pacientes con kwashiorkor-marasmo 403 g/día (268-429) y en los pacientes con kwashiorkor $270 \mathrm{~g} /$ día (000-476).

Tabla: 1

\begin{tabular}{l|l|l|l|l}
\hline Outcome & $\begin{array}{l}\text { Total } \\
(\mathbf{n}=\mathbf{1 7 0})\end{array}$ & $\begin{array}{l}\text { Marasmo } \\
(\mathbf{n}=\mathbf{1 0 6})\end{array}$ & $\begin{array}{l}\text { Kwashiorkor- Marasmo } \\
(\mathbf{n}=14)\end{array}$ & $\begin{array}{l}\text { Kwashiorkor } \\
(\mathbf{n = 5 0 )}\end{array}$ \\
\hline Recuperados & $144(85 \%)$ & $86(81 \%)$ & $10(71 \%)$ & $48(96 \%)$ \\
\hline Muertos & $7(4 \%)$ & $5(5 \%)$ & $2(14 \%)$ & 0 \\
\hline No adherencia & $8(5 \%)$ & $6(6 \%)$ & 0 & $2(4 \%)$ \\
\hline Derivados & $11(6 \%)$ & $9(9 \%)$ & $2(14 \%)$ & 0 \\
\hline
\end{tabular}

\section{Conclusiones}

El tratamiento ambulatorio de pacientes desnutridos severos, excedió las normas mínimas aceptadas internacionalmente para la recuperación, adherencia y tasa de mortalidad. No se encontraron estándares de tiempo empleado y de tasas de ganancia de peso en este tipo de programas. El cuidado del paciente ambulatorio podría proporcionar una estrategia de tratamiento complementario para los centros de alimentación terapéutica. Una investigación más exhaustiva debería comparar la efectividad de las intervenciones de emergencia nutricional en pacientes con desnutrición severa, en centros de internación y centros ambulatorios.

\section{Comentario}

Los resultados del estudio muestran que el tratamiento ambulatorio de la desnutrición severa es factible, bajo circunstancias extremas, como lo son: el hambre, la escasez de alimentos, la alta prevalencia de desnutrición severa y el aumento de la incidencia de infecciones. Tanto la mortalidad, como la tasa de recuperación superaron los estándares mínimos internacionales, aceptados para los centros de alimentación terapéutica, mientras la ganancia de peso fue más baja que las normas mínimas internacionales. La interpretación de estos resultados debe hacerse con suma cautela, porque tanto la recuperación como la muerte de un desnutrido, varía según el perfil epidemiológico de una población (por ejemplo: factores estacionales que condicionan la disponibilidad de alimentos en comunidades netamente agrícolas, carencia de agua potable e incidencia de malaria, entre otras cosas) y el desempeño del sistema de salud en situaciones de emergencia, datos que no fueron relevados en este estudio, constituyendo una limitación metodológica importante que le resta validez externa al trabajo. En los programas de apoyo alimentario, el riesgo habitual es que el alimento entregado para el niño desnutrido se comparta con los demás integrantes de la familia o se venda con el objetivo de satisfacer otras necesidades, situación que obstaculiza la recuperación rápida de los desnutridos y que en muchas ocasiones hace que la desnutrición se perpetúe

Otro tema de discusión, considerado también por los investigadores, se refiere al aporte nutricional realizado a estos niños que por definición son extremadamente vulnerables, con alto riesgo de complicaciones y muerte. Por un lado, el aporte de nutrientes en cuanto a composición y concentración, probablemente no fue el más adecuado para comenzar el tratamiento del marasmo y del kwashiorkor-marasmo (murieron 5 y 2 niños respectivamente, de los 170 que recibieron tratamiento) y en segundo lugar, en ese momento el único alimento enriquecido, de rápida implementación y de fácil uso ambulatorio, disponible a nivel internacional fue el utilizado por el programa ${ }^{2,3,4}$. El aporte nutricional implementado, tuvo una mayor concentración de los nutrientes requeridos y habitualmente recomendados, para comenzar el tratamiento en desnutridos severos, pero como se expresó más arriba era el único disponible para esa situación de emergencia alimentaria y sanitaria.

Conclusiones del comentador: Este estudio, plantea una alternativa a tener en cuenta en comunidades con alta prevalencia de desnutrición severa, donde el tratamiento tradicional (largas estadías en los hospitales) se convierte en otro problema de salud, porque los niños severamente desnutridos están inmunocomprometidos y en peligro de adquirir cualquier tipo de infección, complicando el tratamiento, la recuperación y en muchos casos desencadenando la muerte. Mientras que, con un programa de alimentación ambulatorio los niños estarían menos expuestos a complicaciones (infecciones intrahospitalarias) y por otro lado, las cuidadoras que en general son las madres, no estarían alejadas del hogar, donde suelen tener un rol fundamental en el sustento, mantenimiento y cuidado de los demás integrantes de la familia, habitualmente numerosa y con riesgo de desnutrición. Para finalizar y compartiendo la inquietud de los autores, coincidimos en que es necesario la realización de estudios donde se compare la efectividad del tratamiento tradicional que se realiza en internación, a nivel hospitalario y el tratamiento ambulatorio de los desnutridos severos.

\section{Dra. Nanci Giraudo [ Unidad de Medicina Familiar y Preventiva. Hospital Italiano de Buenos Aires ]}

\section{Referencias}

1. Beaton G, Ghassemi H. Supplementary feeding programs for young children in developing countries. Am J Clin Nutr 1982; 35: 864-916. [PubMed].

2. Waterlow JC. Protein energy malnutrition (1st edn). London: Edward Arnold, 1993.

3. Collins S, Myatt M, Golden B. Dietary treatment of severe malnutrition in adults. Am J Clin Nutr 1998;68: 193-99. [PubMed].

4. Gomez F, Ramos-Galvan R, Frenk S, et al. Mortality in second and third degree malnutrition. J Trop Pediatr 1956;2: 77-83. [PubMed]. 